\title{
Ambient noise energy bursts observation and modeling: Trapping of harmonic structure-soil induced-waves in a topmost sedimentary layer
}

\author{
C. Cornou ${ }^{1, *}$, P. Guéguen ${ }^{1,2}$, P.-Y. Bard ${ }^{1,2}$ \& E. Haghshenas ${ }^{1,3}$ \\ ${ }^{1}$ Laboratoire de Géophysique Interne et Tectonophysique, Université Joseph Fourier, Grenoble, France; \\ ${ }^{2}$ Laboratoire Central des Ponts-et-Chaussées, Paris, France; ${ }^{3}$ International Institute of Earthquake \\ Engineering and Seismology, Teheran, Iran; *now at Swiss Seismological Service, ETH Zürich, \\ Switzerland; e-mail: cornou@seismo.ifg.ethz.ch
}

Received 7 July 2003; accepted in revised form 8 June 2004

Key words: $\mathrm{H}$ over V spectral ratio, microtremors, site effects, structure-soil interaction, urban ground motion

\begin{abstract}
We study the nature of energy bursts that appeared in the frequency range 3-5 Hz in ambient seismic noise recorded in the Grenoble basin (French Alps) during a seismological array experiment. A close agreement is found between the identified azimuths of such noise bursts with the location of an industrial chimney. In-situ measurements of the chimney dynamic characteristics show a coincidence between the frequency of the first harmonic mode of the chimney and the fundamental frequency of a thin surficial layer that overlay the deep sediment fill. The interaction between the chimney and the surficial layer is then numerically simulated using simple impedance models and two soil profiles. Simulations exhibit a satisfactory agreement with observations and suggest that energy bursts result of inertial structure-soil interaction favored by resonance effects between the first harmonic mode of the structure and the fundamental frequency of the topmost layer.
\end{abstract}

\section{Introduction}

Seismic ambient vibrations may be caused by natural or anthropic disturbances such as wind, sea waves, traffic, industrial machinery, etc. In this paper, we are interested in very specific energetic microtremor waveforms observed at various sites within the city of Grenoble, French Alps. These transient-like waveforms, later called noise bursts, have amplitude higher than the mean seismic noise level and propagate within the $3-5 \mathrm{~Hz}$ frequency band, that does not correspond to the fundamental resonance frequency near $0.3 \mathrm{~Hz}$ of the site (Lebrun et al., 2001). We took advantage of a dense array of three-component seismometers installed during spring 1999 within the city for site effects purposes, in order to address the origin and the nature of such noise energy bursts. We first describe the geophysical settings of the Grenoble basin and present the main characteristics of noise bursts. Then, array technique is applied to identify back-azimuth, frequency and apparent velocity of noise bursts. From these first results, the origin of the bursts is discussed and assumed as waves generated by the first higher mode of vibration of an industrial chimney. Simulation of the inertial soil-structure interaction is then carried out in order to confirm this interpretation.

\section{Evidence of noise energy bursts in the Grenoble basin}

\section{Grenoble basin: Geophysical parameters}

The Grenoble basin displayed in Figure 1a is a 3D Y-shaped deep basin filled mostly with late quaternary post-glacial deposits overlaying Jurassic marls and a marly limestone substratum. A deep borehole drilled by the Institut de Radioprotection et de Sûreté Nucleaire (IRSN) in the NE-branch of the valley hit the substratum at $532 \mathrm{~m}$ depth (Nicoud et al., 2002). 

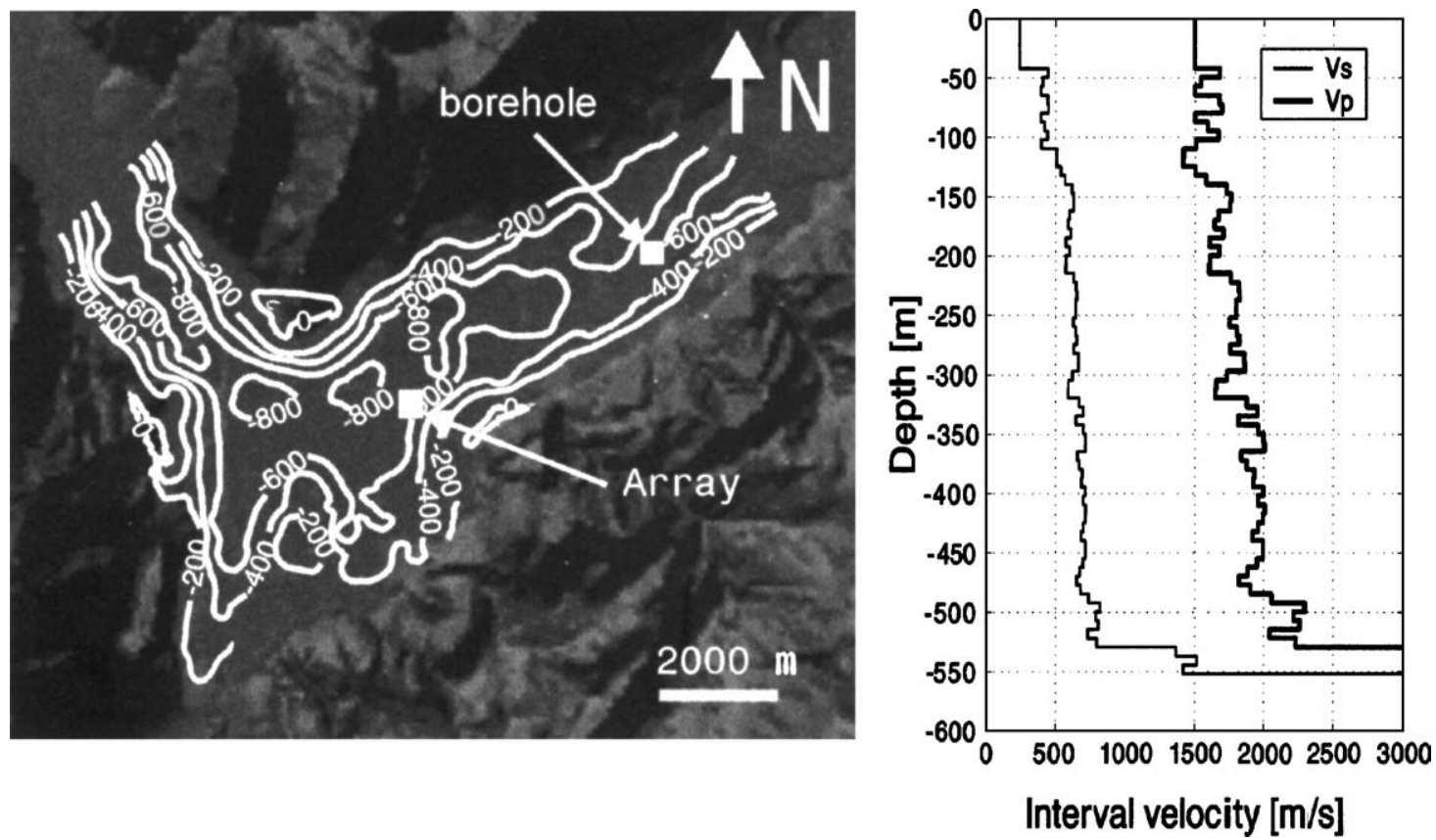

Figure 1. a) Grenoble basin's digital elevation model and, superimposed, the 3D contour map of the basement's depth (white lines) inferred from gravimetric measurements (Vallon, 1999). Depth is indicated in meters. Location of the array and the borehole are also indicated. b) P- (thick line) and S- (thin line) wave interval velocity profiles derived from vertical and offset seismic profiles measurements at the borehole location (Cornou, 2002).

Bouguer anomaly analysis of gravity measurements at more than 400 points (Vallon, 1999) provided the substratum topography that fits at the borehole location with the substratum depth evaluated through seismic and borehole measurements (Nicoud et al., 2002). Logging operations performed in the borehole, as well as the investigation of contribution of vertical and offset seismic profiles show that the P-wave velocity varies between 1450 and $2200 \mathrm{~m} / \mathrm{s}$, and the $S$-wave velocity, between 240 and $800 \mathrm{~m} / \mathrm{s}$ from the surface down to the bedrock (Cornou, 2002). Velocity profiles are displayed in Figure lb. The S-wave velocity profile exhibits a lowest velocity value $(240 \mathrm{~m} / \mathrm{s})$ within a $40 \mathrm{~m}$ thick surficial layer that induces a $S$-wave velocity contrast of about two with the underneath layer. This low $\mathrm{S}$-wave velocity topmost layer was very recently confirmed through cuttings from a second borehole drilled nearby the previous one (Lemeille, personal communication) that have shown a major sands/clay contrast at $40 \mathrm{~m}$ depth. Besides these measurements, Lebrun et al. (2001) performed an extended H/V microzonation study based on Nakamura's method (Nakamura, 1989; see Bard, 1998 for a review of the method) within the area of Grenoble. They observed a resonance frequency of $0.3 \mathrm{~Hz}$ in the central part of the basin and. another one, in some part of the city, near $3 \mathrm{~Hz}$ that they assigned to a resonance of a very surficial layer.

\section{Noise energy bursts}

An array composed of 29 three-component seismic sensors was installed in the city as indicated in Figure 2 and operated from February to May 1999. Sensors were arranged in concentric rings: 16 L22 Mark Products sensors (with a flat response between 2 and $50 \mathrm{~Hz}$ ) were located in two inner rings with a maximum $80 \mathrm{~m}$ aperture, 12 wider band sensors (3 Lennartz Le3D-5s and 9 Guralp CMG40-20s, with a flat response from 0.2 and 0.05 to $50 \mathrm{~Hz}$, respectively) were installed in a maximum $1 \mathrm{~km}$ aperture outer ring and one CMG40-20s sensor added at the center of the array. Sensor locations were precisely determined using static GPS measurements (precision of about $0.3 \mathrm{~m}$ ). Sensors were connected either to Reftek-72A2 or to a Minititan-3XT recorder. These instruments are part of the portable Lithoscope and RAM mobile national networks (http://www-lgit.obs.ujf-grenoble.fr/ equipements-nat/equipement-nat.htm). Data were continuously recorded, time synchronization was provided 

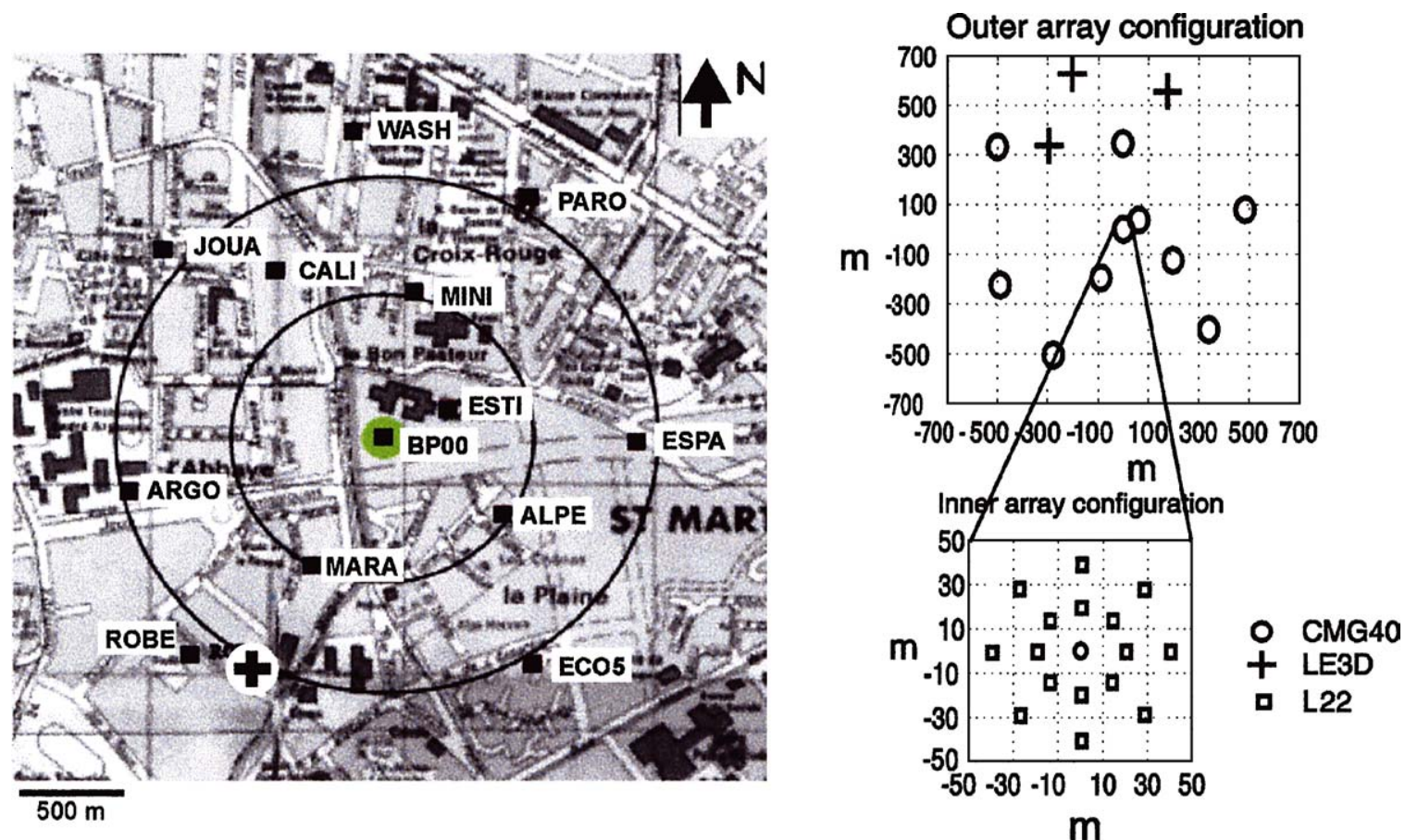

Figure 2. (left) Approximative geographical array location, cross indicates location of the chimney, (right) Outer and inner array configuration. The BP00 station is located at the center of the inner array.

by continuous GPS receivers (time accuracy less than $1 \mathrm{~ms}$ ) and the sampling rate was fixed to $125 \mathrm{~Hz}$ on each channel. Figure 3 displays examples of noiseenergy bursts and their corresponding Fourier spectra amplitude. A statistical study of the noise bursts has been performed over one week from the 1 st to the 7 th of February 1999, using four 2 h-windows per day: noise-energy bursts appear mainly during night within the 2 to $5 \mathrm{~Hz}$ frequency band, in relation with a low mean noise level during night. Over the whole $56 \mathrm{~h}$ investigated period, 100 noise bursts have been identified with a mean duration of $25 \mathrm{~s}$. Similar noise bursts propagating within the same frequency range were also observed throughout the eastern part of the basin from other dense array measurements of noise (Bettig et al., 2001; Cornou, 2002).

\section{Noise bursts propagation parameters}

In this study, a total of $12 \mathrm{~h}$ of noise recordings have been considered (Table I). First, we have detected noise bursts as follows: 1) signals are filtered between 2 and $6 \mathrm{~Hz}$ using a Butterworth filter; 2) for each of the three components, less stationary time windows are evaluated using a STA/LTA short term/long term trigger algorithm $(\mathrm{STA}=1 \mathrm{~s}$ and LTA $=20 \mathrm{~s}) ; 3$ ) only time win- dows exhibiting non-stationary simultaneously on the three components are kept. Over these $12 \mathrm{~h}$ of study, 63 noise bursts have thus been detected (Table I). Next, we used the reallocated smoothed Wigner-Ville pseudospectrum time-frequency distribution to sharply localizing the energy of the signal in the time-frequency plane. This time-frequency representation is indeed more appropriate than the classical Fourier-based ones, when precise confinement of the energy in the timefrequency plane is required (Auger and Flandrin, 1995; Pedersen et al., 2002). Time-frequency points where phase is stationary (ridges) are then extracted and we only kept those points location $\left(t_{\mathrm{i}}, f_{\mathrm{i}}\right)_{i=1, N}$, where $N$ is the number of points of the ridges, that corresponds to the $40 \%$ most energetic part of the energy spectrum density (Figure 4). The so-called MUSIC algorithm (Multiple Signal Characterization; Schmidt, 1981 and 1986) array technique is then applied for characterizing the noise bursts propagation parameters (apparent velocity, back-azimuth). Since the array technique is reliable when sensor-to-sensor signal coherency is high enough, only the inner array was used for the array analysis. Besides, MUSIC requires the a priori knowledge of the number of waves propagating across the array at a given time. This number was evaluated using the procedure described in Cornou et al. (2003a). In this study, 
Time series
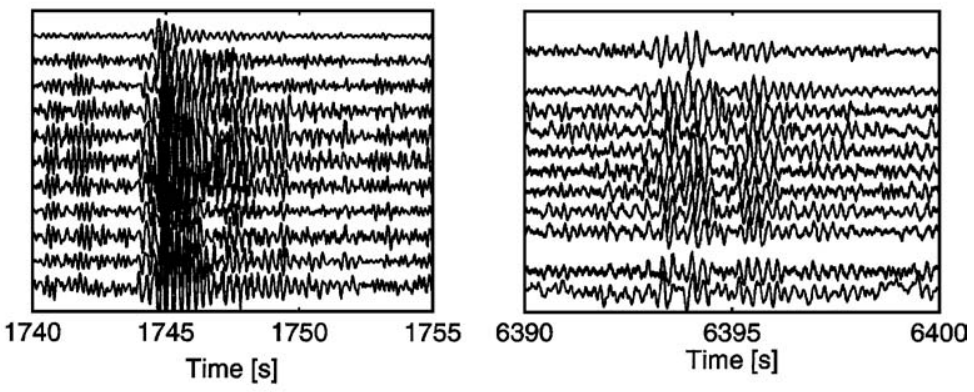

Fourier amplitude spectra $(\mathrm{nm})$

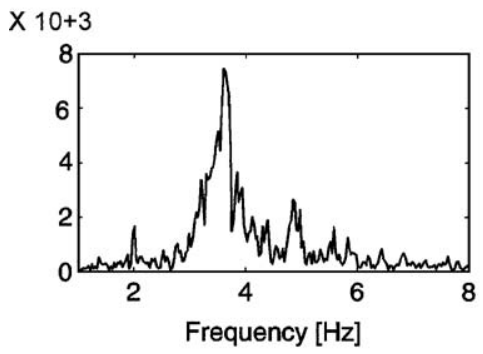

(a)

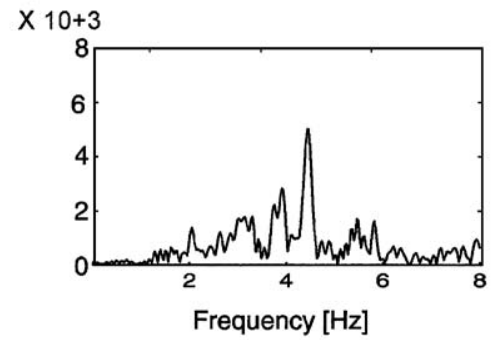

(b)

Figure 3. Example of two noise energy bursts (a) and (b) observed on the vertical component (velocity time histories) of the inner array sensors (top) and corresponding Fourier spectra amplitude (bottom). Signals are not filtered.

the number of signals is most often one and does not exceed the value of two. Array analysis was performed separately on each component at each time $t_{i}$ within the frequency range $\left[f_{i}-0.5, f_{i}+0.5 \mathrm{~Hz}\right]$ in increments of $0.1 \mathrm{~Hz}$. The time window length of analysis was fixed to $2 /\left(f_{i}-0.5\right)$ in order to warrant at least two wave periods for analysis. Then, for each frequency, we evaluated the power spectrum of the identified signals and retained those propagation parameters that have provided the most powerful spectra (Cornou et al., 2003a). Finally, we only kept those waves identically identified on the three components together within a time, back-azimuth

Table 1. Number of noise energy bursts detected by the array

\begin{tabular}{lll}
\hline Date & Time interval (TU) & Number of bursts \\
\hline $1999 / 03 / 29$ & $01 \mathrm{~h} 00-03 \mathrm{~h} 00$ & 13 \\
& $20 \mathrm{~h} 00-22 \mathrm{~h} 00$ & 10 \\
$1999 / 03 / 31$ & $01 \mathrm{~h} 00-03 \mathrm{~h} 00$ & 30 \\
& $05 \mathrm{~h} 00-07 \mathrm{~h} 00$ & 6 \\
$1999 / 04 / 01$ & $05 \mathrm{~h} 00-07 \mathrm{~h} 00$ & 5 \\
& $20 \mathrm{~h} 00-22 \mathrm{~h} 00$ & 2 \\
\hline
\end{tabular}

and a frequency deviation of $0.2 \mathrm{~s}, 10^{\circ}$ and $0.1 \mathrm{~Hz}$, respectively.

Figure 5 displays histograms of a) back-azimuth, b) frequency and c) apparent velocity of noise bursts after array processing. Distribution of frequency and apparent velocity as a function of back-azimuth are depicted in Figures 5d and 5e. Since the number $N$ of time-frequency points used for array analysis may vary from burst to burst (depending mainly of the burst duration), we have duplicated the propagation parameter estimates (frequency, back-azimuth, apparent velocity) such as bursts have finally the same number of estimates $(N)$. The bursts arrival direction is clearly N200. Frequencies ranges from 3 to $5 \mathrm{~Hz}$, apparent velocities mostly around $300 \mathrm{~m} / \mathrm{s}$ and no specific distribution of velocity as a function of frequency have been observed.

\section{Anthropic or/and natural origin? Some insights}

The N200 back-azimuth points at a $65 \mathrm{~m}$ high chimney located nearby ROBE seismic station as indicated in Figure 2 (left). For the two bursts shown in Figure 3, 

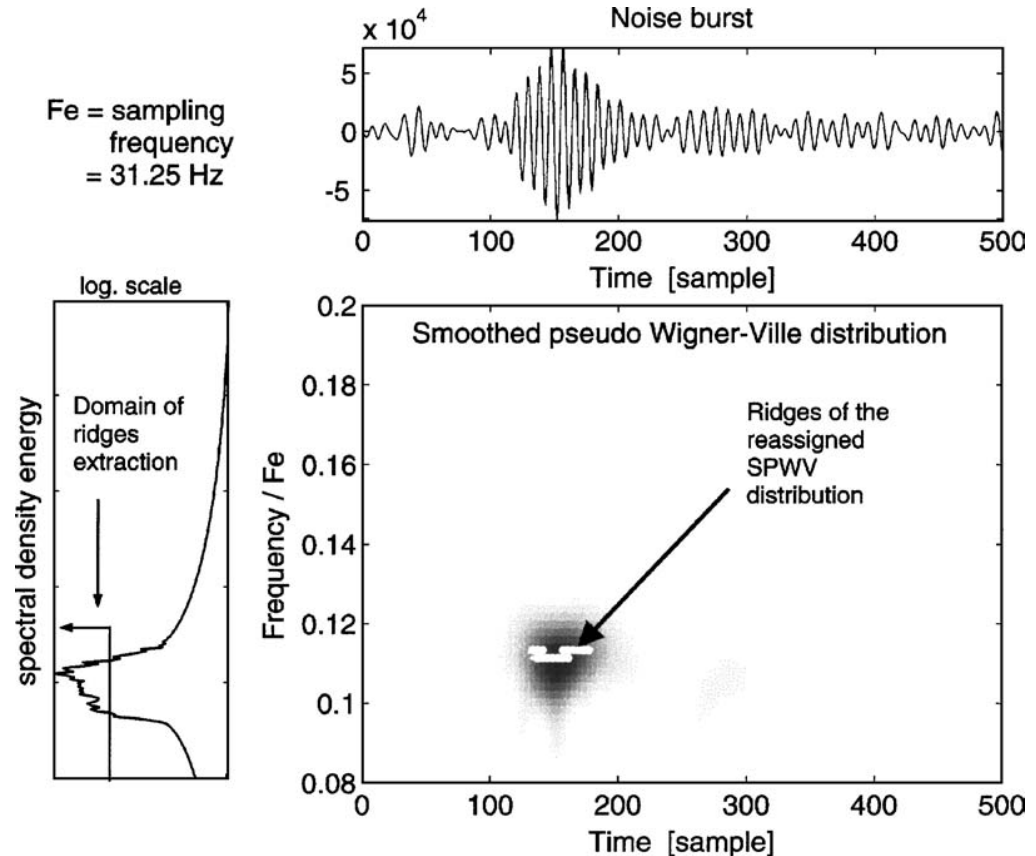

Figure 4. Smoothed Pseudo Wigner-Ville distribution (bottom right) of a noise burst (top) and location (ridges, bottom right) of the $40 \%$ most energetic part of the energy density spectrum. The reassigned SPWV is not shown here.
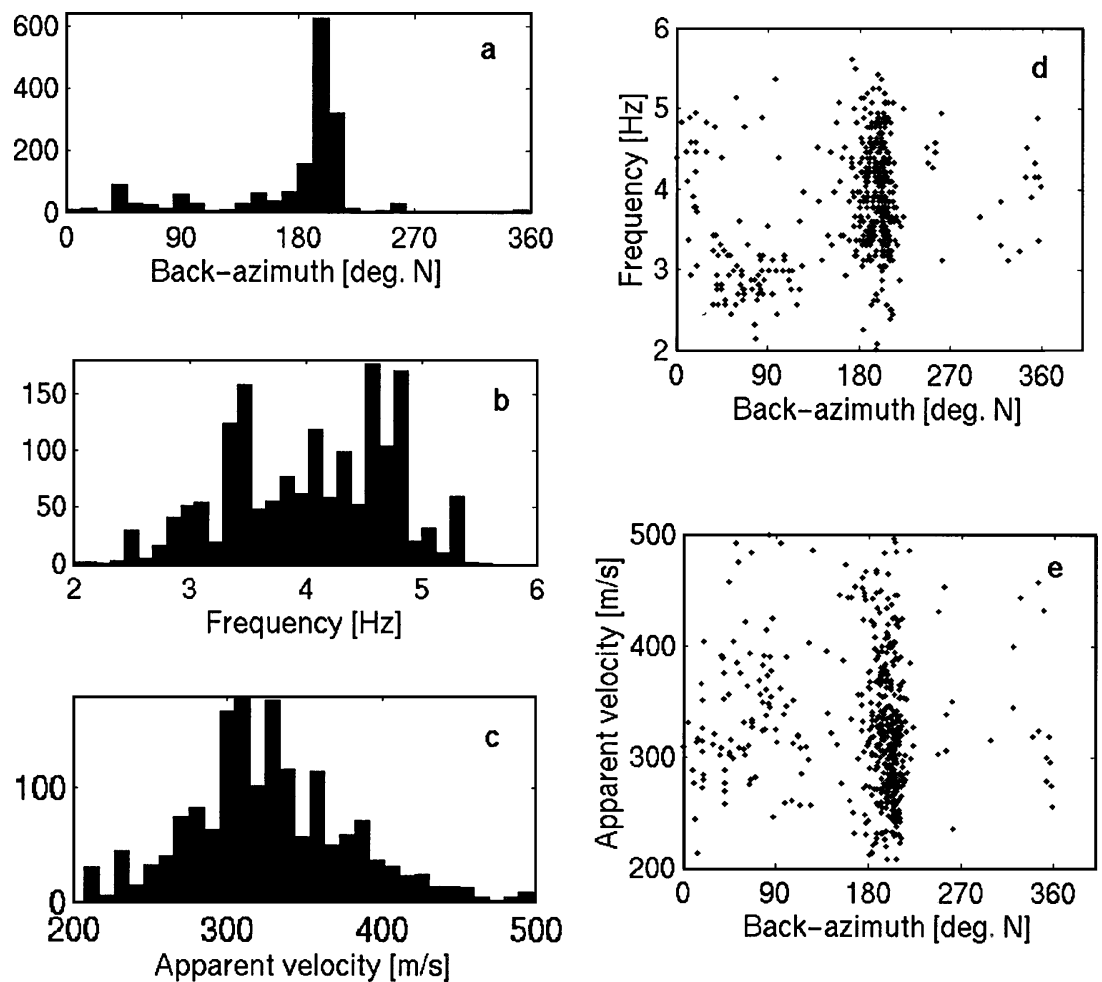

Figure 5. Results from the array analysis: histograms of a) back-azimuth, b) frequency and c) apparent velocity; distribution of frequency (d) and apparent velocity (e) as a function of back-azimuth. 
(a)
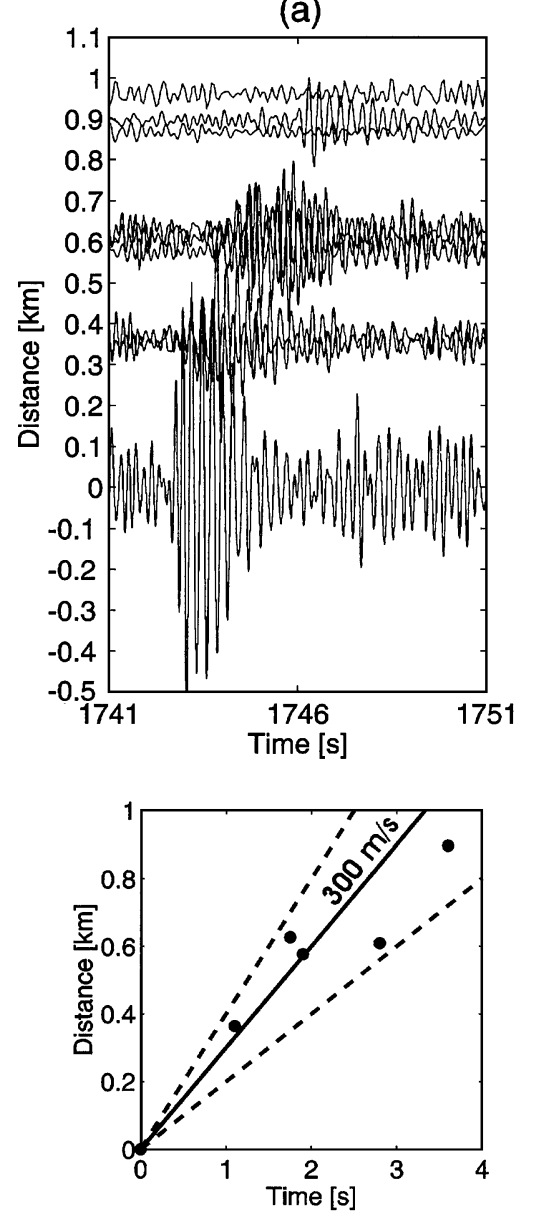

(b)
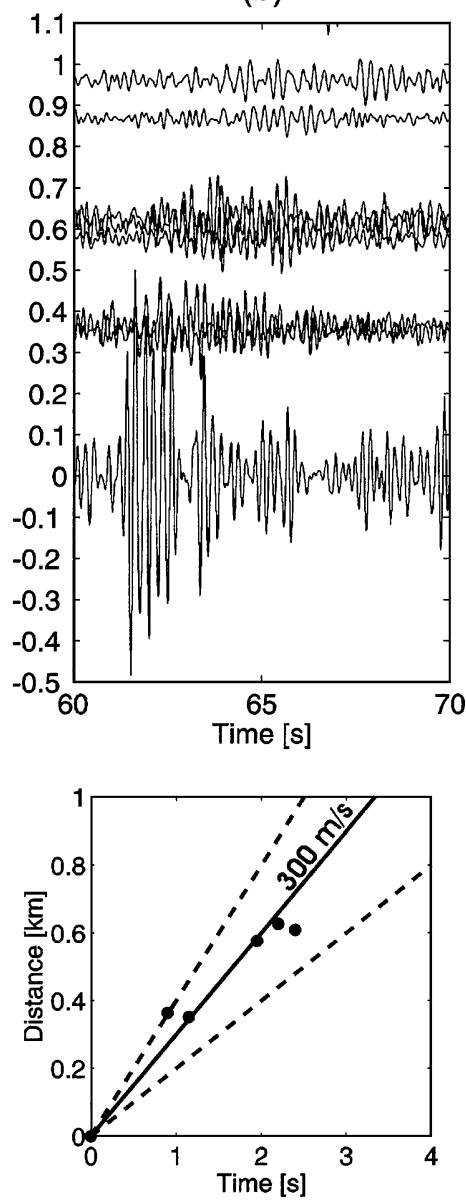

Figure 6. (Top) Outer array sensors recordings (vertical component, velocity time histories) of the noise bursts displayed in Figure 3 as a function of the sensor-to-ROBE station distance. (Bottom) Time delay between the burst onset at the outer array sensors and the onset at the ROBE station as a function of the sensor-to-ROBE station distance. Only the clearest bursts onsets were picked. The $300 \mathrm{~m} / \mathrm{s}$ propagation velocity is indicated by the black line, while the 200 and $400 \mathrm{~m} / \mathrm{s}$ propagation velocities are indicated by the dashed black line.

we displayed in Figure 6 the recorded signal (top) at the outer array sensors as a function of the distance from the ROBE seismic station and the related hodochrons (bottom). Amplitudes of bursts strongly decrease with distance and time delays of bursts arrivals are consistent with the $300 \mathrm{~m} / \mathrm{s}$ propagation velocity given by array analysis. This decay is also observed for all other bursts coming from the N200 back-azimuth. Results from array analysis and these last observations strongly suggest that the phenomenon at the origin of the noise bursts emission is at the chimney location.

Time delay between the burst onset at the outer array sensors and the onset at the ROBE station as a function of the sensor-to-ROBE station distance.

Numerical and experimental studies have already shown that the vibrations of structures radiate diffracted waves into the soil through their foundation (Jennings, 1970; Kanamori et al., 1991; Wirgin and Bard, 1996; Guéguen et al., 2000a). Such effects may be important when the soil-structure system frequency coincides with the underlying soft layer's resonance frequency (Kanamori et al., 1991; Guéguen et al., 2002): induced waves are indeed trapped within the layer and propagate as surface waves, which form packets having a spindle-shape envelope, up to several hundred meters (Guéguen et al., 2000a). Moreover, ambient vibration can be used as building-excitement source for measuring structural parameters of the building such as natural frequency, damping factor, torsion parameters (e.g. Ivanovic et al., 2000; Dunand et al., 2001).

In order to study the possible effects of the chimney vibrations to generating noise bursts, natural 

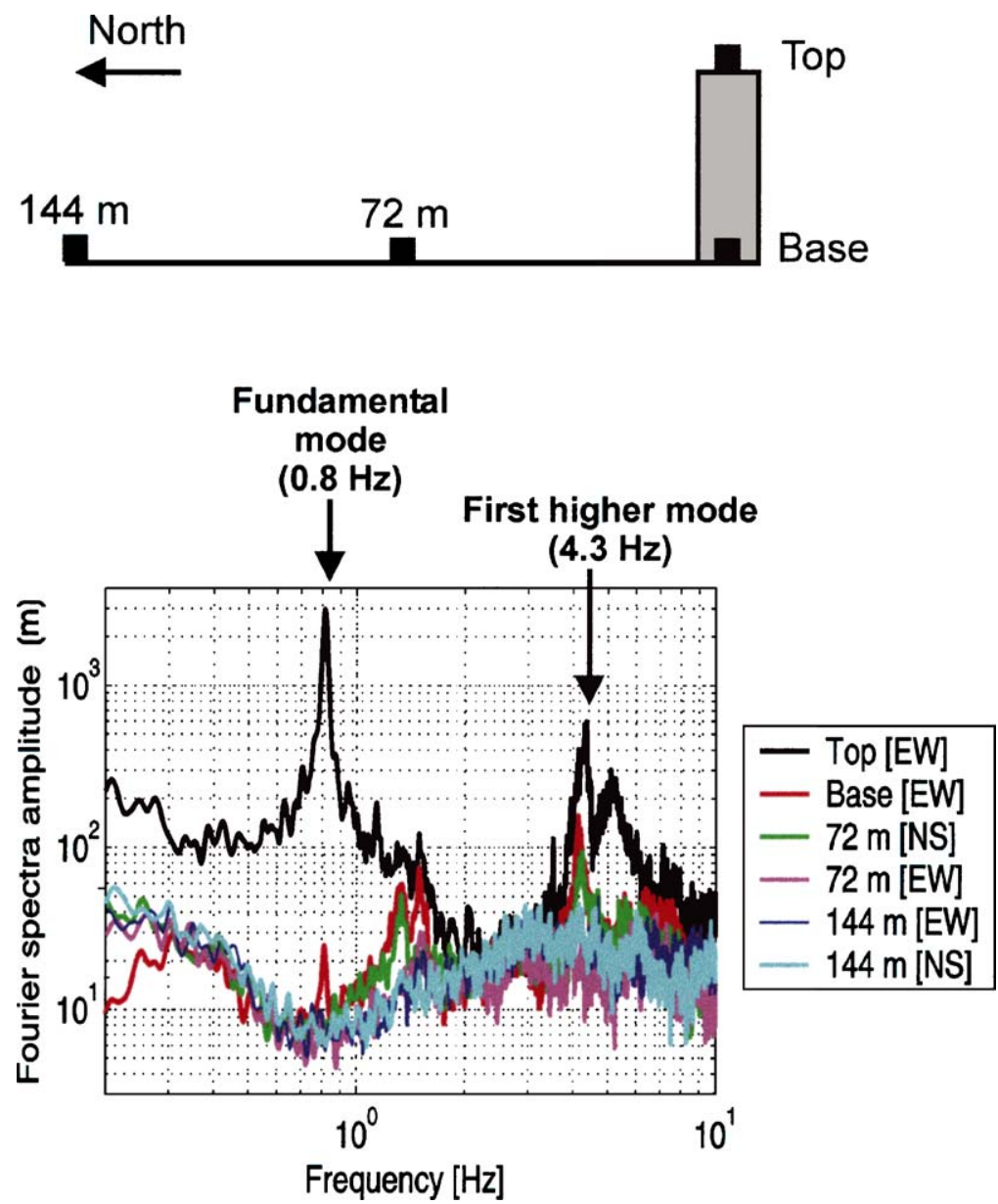

Figure 7. (Top) Sensors configuration during the in-situ measurements of the chimney dynamic characteristics; (Bottom) Fourier spectra amplitudes of $300 \mathrm{~s}$ of noise (velocity time histories) recorded at the top (roof) and the inner base of the structure (EW component), and at 72 and $144 \mathrm{~m}$ far from the structure (EW and NS components).

frequencies of this structure have been first measured using ambient vibration simultaneously recorded at the top and the base of the chimney (inside the structure). In addition to these measurements, two seismic stations were deployed at 72 and $144 \mathrm{~m}$ far from the structure as depicted in Figure 7 (top). Data were recorded using Lennartz Le3D-5s sensors connected to the CityShark seismic station (Chatelain et al., 2000). The transfer function of the structure indicates a fundamental vibration mode at $0.8 \mathrm{~Hz}$ and a first higher resonance mode at $4.3 \mathrm{~Hz}$. Figure 7 (bottom) shows the Fourier spectra amplitudes recorded by the four sensors. Spectral contribution of the fundamental frequency of the chimney is not observed any more at 72 and $144 \mathrm{~m}$ far from the structure. On the contrary, the first higher resonance mode seems to contribute to the ground motion at least up to $144 \mathrm{~m}$, although the related back-released energy into the soil by the chimney is less important than for the fundamental mode (Figure 7). Besides, it has to be pointed out that some other dominant frequencies appear on the spectra recorded at the top and the base within the $1.5-2 \mathrm{~Hz}$, and the $3.5-5 \mathrm{~Hz}$ frequency ranges that might indicate an anisotropy of the structure.

It has been previously mentioned that a $40 \mathrm{~m}$ deep layer with low $\mathrm{S}$-wave velocity has been observed at the borehole location. However, the array is located too far away from the borehole location (around $5 \mathrm{~km}$ ) to reasonably assume the layer is first continuous and second, exists with similar characteristics (thickness and seismic velocities) at the array site. Nevertheless, Lebrun (1997) has observed on H/V ratio computed on seismic ambient vibrations at various sites within the basin a secondary peak near $3 \mathrm{~Hz}$, which was attributed 

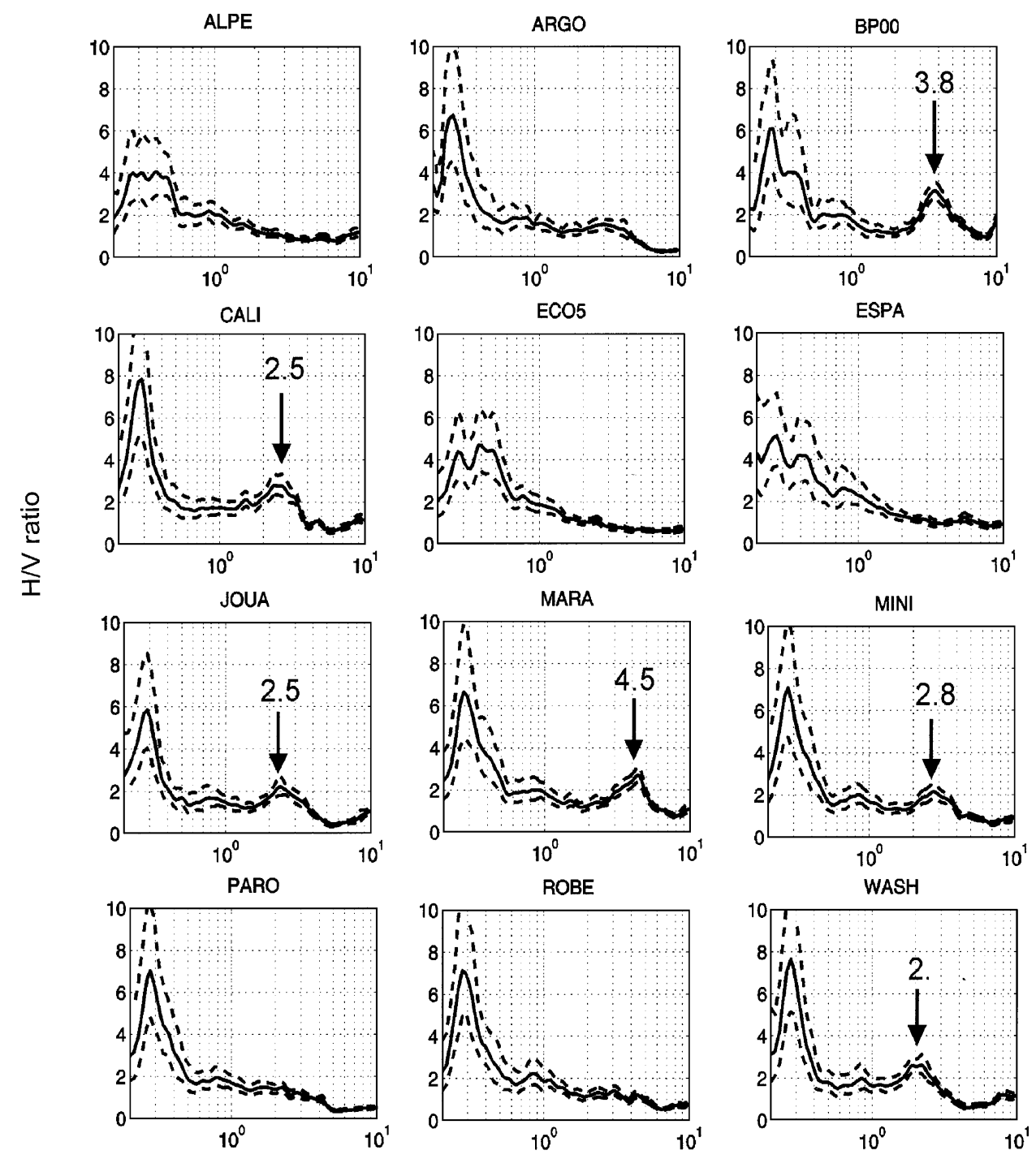

Frequency $[\mathrm{Hz}]$

Figure 8. H/V ratio $+/-$ standard deviation computed on the most stationary parts of $2 \mathrm{~h} 00$ seismic ambient noise recorded at the outer array sites (see Figure 2 for array sites location). When a secondary peak is observed on $\mathrm{H} / \mathrm{V}$ ratios, the $\mathrm{H} / \mathrm{V}$ peak frequency is indicated.

to the resonance of a very surficial layer in the depth range of 20-40 m. Effects of a topmost thin soil layer overlaying the sediment fill on $\mathrm{H} / \mathrm{V}$ peaks was also numerically (Cornou et al, 2003b) or experimentally observed in Quito and Pujili by Guéguen et al. (1998, $2000 \mathrm{~b}$ ). We have thus computed the $\mathrm{H} / \mathrm{V}$ ratio on the most stationary time windows (in order to avoid effects of transients produced by urban near-sources) of $2 \mathrm{~h}$ of ambient vibrations simultaneously recorded by the array sensors. The most stationary windows were selected using a STA/LTA anti-trigger algorithm, where
$\mathrm{STA}=0.5 \mathrm{~s}$ and LTA $=30 \mathrm{~s}$ and the time window length was fixed to $25 \mathrm{~s}$ when computing H/V spectral ratio. $\mathrm{H} / \mathrm{V}$ curves computed at the outer array sensors are displayed in Figure 8. Except the fundamental resonance frequency of the basin around $0.3 \mathrm{~Hz}$, most of the sites located in the eastern side of the array exhibit a secondary $\mathrm{H} / \mathrm{V}$ peak with related frequencies varying from 2.5 to $4.5 \mathrm{~Hz}$ (Figure 8). Secondary $\mathrm{H} / \mathrm{V}$ peaks occurring at frequencies ranging from 3.7 to $4.4 \mathrm{~Hz}$ are also observed at the inner array sensors (Figure 9). In order to check or not the existence of such secondary 


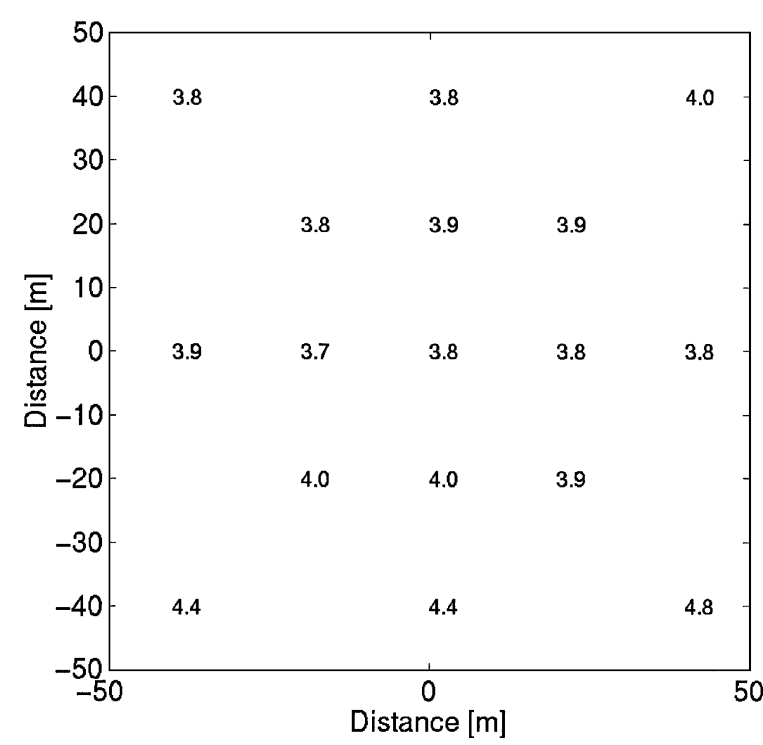

Figure 9. Frequencies (Hz) of the secondary peak observed on $\mathrm{H} / \mathrm{V}$ ratios computed at inner array sites using the most stationary time windows of $2 \mathrm{~h} 00$ noise recordings.

$\mathrm{H} / \mathrm{V}$ peaks at a larger geographical scale, we have computed $\mathrm{H} / \mathrm{V}$ ratios using noise recordings from Lebrun et al. (2001). Secondary peaks occurred in most $\mathrm{H} / \mathrm{V}$ measurements at frequencies changing gradually from high values at the south-east to low values at the most central part of the basin as indicated in Figure 10. The existence of; these secondary $\mathrm{H} / \mathrm{V}$ peaks over a large area

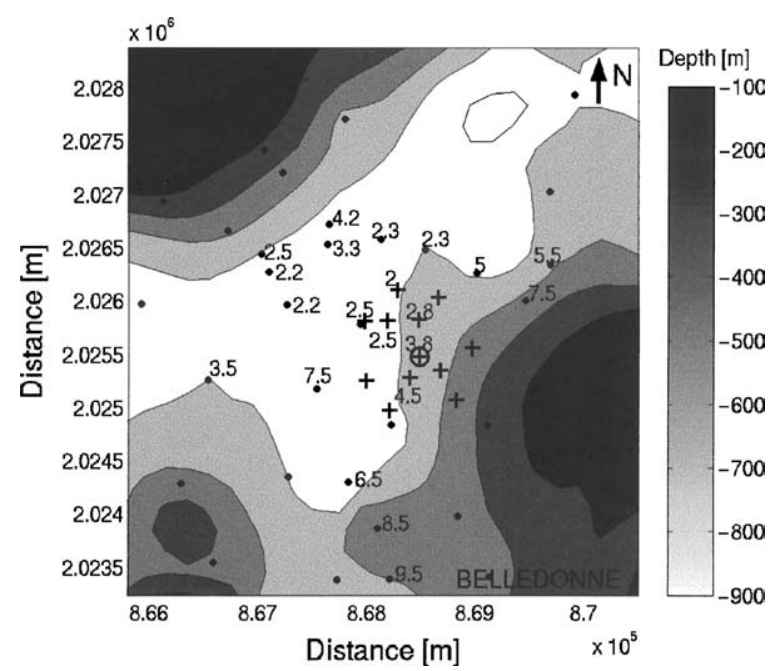

Figure 10. Grenoble basin's depth contour map derived from gravimetric measurements (Vallon, 1999); dots indicate location of H/V measurements performed by Lebrun et al (2001) and crosses indicate location of outer array sensors (the BP00 station located at the center of the inner array is indicated by a circled-cross). When a secondary peak in observed on $\mathrm{H} / \mathrm{V}$ curves, its related frequency is indicated. strongly argues a low-velocity topmost layer throughout the eastern part of the basin. Regarding the array site and assuming a constant $S$-wave velocity of $300 \mathrm{~m} / \mathrm{s}$, the deposit thickness should also vary from 15 to $30 \mathrm{~m}$ throughout the array site.

The frequency of the first higher mode of the chimney is close to both the resonance frequency of this topmost layer and the frequency content of noise bursts: we therefore suggest that the waves radiated from the chimney at its fundamental mode have a too large wavelength to be trapped, and propagate essentially downwards, while those emitted at the first higher mode are trapped within the layer, propagate as surface waves and can thus be detected over long distances. At this point, however, the frequency content variability of the observed noise bursts has to be discussed: noise bursts presented in Figures 3 and 6 do not have indeed the same dominant frequency content while, in principle, they should if only pure harmonic structure-soil induced-wave effects is assumed. In order to hit these inconsistencies, we have first computed the Fourier amplitude spectra of 12 noise bursts that exhibited the highest signal-to-noise ratio. The time window length used for computing Fourier spectra is $15 \mathrm{~s}$ and Figure 11 displays recorded spectra at some array sites. Except two bursts exhibiting a dominant frequency around $3.6 \mathrm{~Hz}$ (among which the burst presented in Figures $3 \mathrm{a}$ and $6 \mathrm{a}$ ), the other bursts exhibit a dominant frequency between 4 and $5 \mathrm{~Hz}$. For the MARA station that is the nearest seismic station located to the northeast of the chimney, a peak at $1.5 \mathrm{~Hz}$ appears for all the bursts on the east-west component Fourier amplitude spectra. This frequency, that is slightly observed at the BP00 station (Figure 2) but not at other array sites presented in Figure 11, is similar to the frequency of a peak observed on the east-west Fourier amplitude spectra recorded at the top, the base and at $72 \mathrm{~m}$ far from the chimney (Figure 7). These observations suggest 1) the origin of the chimney vibration in producing all the observed noise bursts and 2) a possible anisotropy of the chimney response as previously mentioned. Then, during the experiment conducted to evaluate the resonance modes of the structure, the chimney was mainly excited by a weak wind that was strong enough to generate inertial soil-structure interaction, but not for generating observable noise bursts. A moderate-to-strong wind or some additive internal excitations produced by the burning of different combustible types (carbon, wood or animal meal for this plant) have thus to be involved for allowing the structure to release back into the soil enough energy in order to produce noise bursts. In 

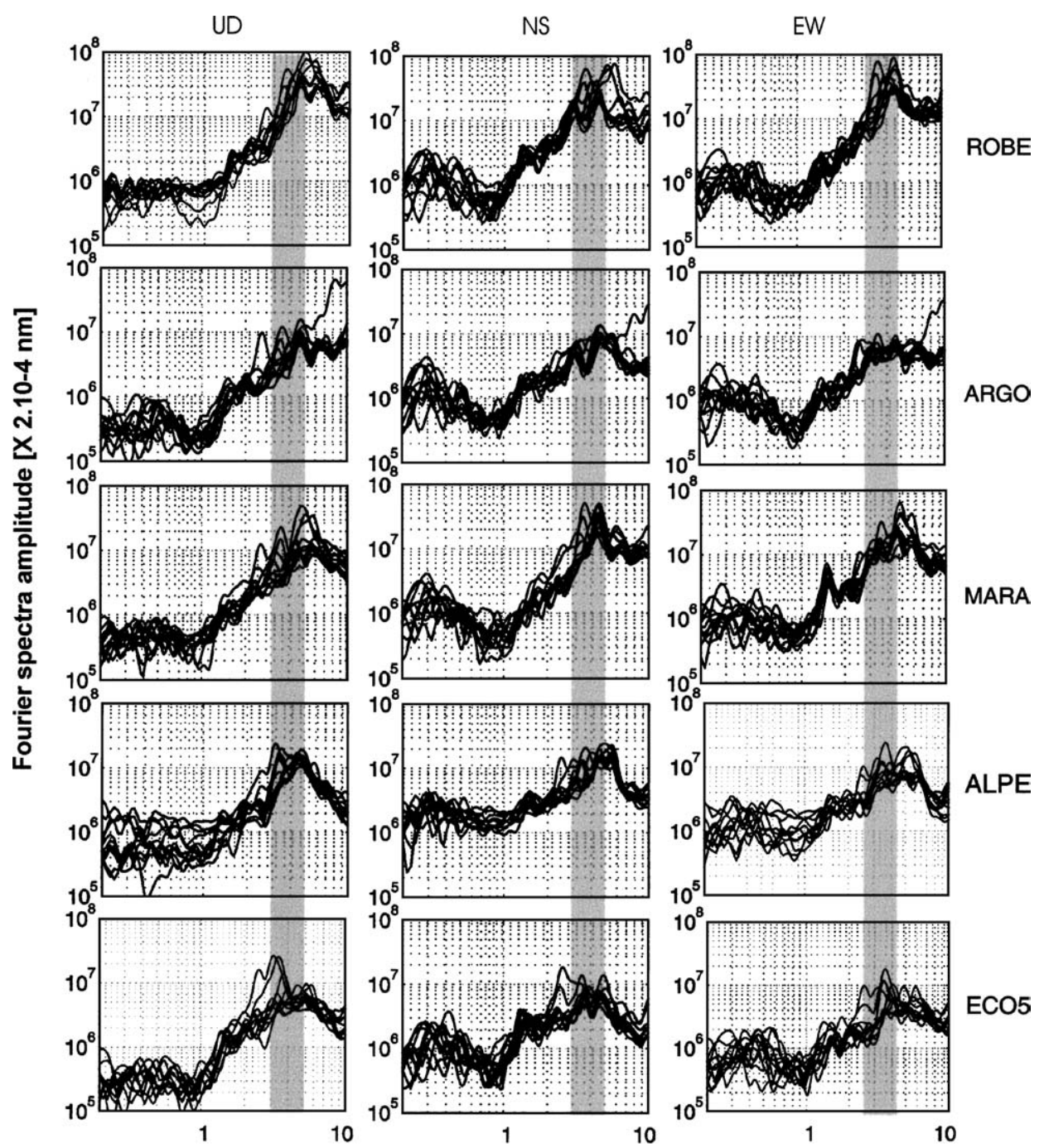

\section{Frequency $[\mathrm{Hz}]$}

Figure 11. Three components of the Fourier amplitude spectra observed at some array sites (see Figure 2 for location of the seismic stations), using the twelve noise bursts that exhibited the highest signal-to-noise ratio. The time window length for Fourier spectra computation was fixed to $15 \mathrm{~s}$. Names of the seismic stations considered here are indicated on the right. The gray shaded area indicates the $3-5 \mathrm{~Hz}$ frequency band.

such a case, wind properties (strength and direction), burning process types and possible anisotropy of the structure might shift the resonance frequencies of the chimney or favored a specific frequency, resulting in a variability of the bursts dominant frequency content. Other hypothesis involving effects of machinery only such as pumps or impulsive shocks (delta-like signals) for explaining noise bursts do not have to be turned on but are rather unlikely: in the first case, the burst frequencies should be sustained and they are not; and in the second case, the signals, only filtered by the soil, should be strictly similar from burst to burst.

\section{Modeling of structure-soil interaction}

In order to confirm the relation between the bursts and the chimney, the vibrations of the tower and its induced effects into the soil have been modeled, following a two-step procedure. First, a free-vibration analysis of the soil-structure system assumed as a uniform cantilever-beam allows to obtaining its mode shapes and frequencies and its total damped motion. Second, the induced base moment and shear force are applied at the surface of a stratified half-space, and the resulting motion at various distances far from the chimney are 
estimated using the discrete wave number technique (see Guéguen et al., 2000a for the technique).

The chimney is made of concrete shaft of $65 \mathrm{~m}$ height $H$ with external $D e$ and internal $D i$ diameter of 6 and $5.25 \mathrm{~m}$, respectively, leading to inertia! value $I$ equal to $18.7 \mathrm{~m}^{4}$. and mass equal to $11.310^{3} \mathrm{~kg} / \mathrm{m}$ Since no detailed knowledge are available on the quality of the material, concrete Young's modulus $E$ has been considered equal to the average Young's modulus usually considered for such material, i.e. $2010^{9} \mathrm{~Pa}$. For sake of simplicity, and because of the uniform chimney, the following analysis considers the tower having uniform properties along its length. The free-vibration equation of motion for this distributed-parameter system is then (Clough and Penzien, 1993):

$$
\mathrm{EI} \frac{\partial^{4} v(x, t)}{\partial x^{4}}+\bar{m} \frac{\partial^{2} v(x, t)}{\partial t^{2}}=0
$$

where constants EI and $\overline{\mathrm{m}}$ represent the flexural stiffness and the uniform mass per unit length. Since EI and $\overline{\mathrm{m}}$ are constants, one form of this equation can be obtained easily by separation of variables using

$$
v(x, t)=\phi(x) Y(t)
$$

which indicates that the free-vibration motion is a specific shape $\phi(\mathrm{x})$ having a time-dependent $Y(t)$ amplitude. Adopting the prime and dot notations to indicate partial derivatives with respect to $\mathrm{x}$ and $\mathrm{t}$ respectively, and substituting Eqs. (2) into (1) gives

$$
\phi^{\prime \prime \prime \prime}(x) Y(t)+\frac{\bar{m}}{\mathrm{EI}} \phi(x) \ddot{Y}(t)=0
$$

Dividing by $\phi(x) Y(t)$, the variables can be separated as follows:

$$
\frac{\phi^{\prime \prime \prime \prime}(x)}{\phi(x)}+\frac{\bar{m}}{\operatorname{EI}} \frac{\ddot{Y}(t)}{Y(t)}=0
$$

Because the two terms of Eq. (4) are function of $x$ and $t$ only, the equation may be satisfied for arbitrary values of $x$ and $t$ only if each term is a constant in accordance with

$$
\frac{\phi^{\prime \prime \prime \prime}(x)}{\phi(x)}=-\frac{\bar{m}}{\mathrm{EI}} \frac{\ddot{Y}(t)}{Y(t)}=a^{4}
$$

for which the single constant is designed as $\mathrm{a}^{4}$ for following mathematical convenience. This equation yields two ordinary differential equations

$$
\begin{aligned}
& \ddot{Y}(t)+\omega^{2} Y(t)=0 \\
& \phi^{\prime \prime \prime \prime}(x)-a^{4} \phi(x)=0
\end{aligned}
$$

where $a^{4}=\omega^{2} \bar{m} /$ EI and $\omega$ is the circular frequency of the excitation. The first of these equations is the classical free-vibration equation for an undamped singledegree-of-freedom (SDOF) system depending upon the initial displacement and velocity conditions, solved by

$$
Y(t)=Y(0) \cos \omega t+\frac{\dot{Y}(0)}{\omega} \sin \omega t
$$

The second equation in Eq. (6) can be solved in the usual way by introducing a solution of the form

$$
\phi(x)=B \exp (s t)
$$

leading to

$$
\left(s^{4}-a^{4}\right) B \exp (s t)=0
$$

from which the four roots are $s_{1,2}= \pm$ ia and $s_{3,4}= \pm$ a.

Substituting each of roots into Eq. (8) separately and adding the resulting four terms, one obtains the following complete solution

$$
\begin{aligned}
\phi(x)= & B 1 \exp (i a x)+B 2 \exp (-i a x)+B 3 \exp (a x) \\
& +B 4 \exp (-a x)
\end{aligned}
$$

where B1, B2, B3 and B4 must be treated as complex constants. Then, expressing the exponential functions in terms of their trigonometric and hyperbolic equivalents and setting the entire imaginary part of the right hand side of this equation to zero lead to

$$
\begin{aligned}
\phi(x)= & A_{1} \cos a x+A_{2} \sin a x+A_{3} \cosh a x \\
& +A_{4} \sinh a x
\end{aligned}
$$

where $A_{1}, A_{2}, A_{3}$, and $A_{4}$ are real constants, which have to be evaluated so as to satisfy the known boundary conditions (displacement, slope, moment or shear) at the limits of the beam. In the case of the chimney considered as cantilever uniform beam, the four boundary conditions to be satisfied are

$$
\begin{array}{cc}
\phi(0)=0 & \phi^{\prime}(0)=0 \\
M(H)=\mathrm{EI} \phi^{\prime \prime}(H)=0 & V(H)=\mathrm{EI} \phi^{\prime \prime \prime}(H)=0
\end{array}
$$


Substituting Eq. (11) and its derivative expressions into these equations gives

$$
\begin{aligned}
\phi(0)= & (A 1 \cos 0+A 2 \sin 0+A 3 \cosh 0 \\
& +A 4 \sinh 0)=0 \\
\phi^{\prime}(0)= & a(-A 1 \sin 0+A 2 \cos 0+A 3 \sinh 0 \\
& +A 4 \cosh 0)=0 \\
\phi^{\prime \prime}(H)= & a^{2}(-A 1 \cos a H-A 2 \sin a H \\
& +A 3 \cosh a H+A 4 \sinh a H)=0 \\
\phi^{\prime \prime \prime \prime}(H)= & a^{3}(A 1 \sin a H+A 2 \cos a H+A 3 \sinh a H \\
& +A 4 \cosh a H)=0
\end{aligned}
$$

The first two equations of Eq. (13) yield A3 = $-\mathrm{A} 1$ and $\mathrm{A} 4=-\mathrm{A} 2$. Substituting these equalities into the last two equations of Eq. (13) and expressing the result in matrix form, one obtains

$$
\begin{aligned}
& {\left[\begin{array}{cc}
(\cos a H+\cosh a H) & (\sin a H+\sin a H) \\
(\sinh a H-\sin a H) & (\cos a H+\cos a H)
\end{array}\right]} \\
& \times\left\{\begin{array}{l}
A 1 \\
A 2
\end{array}\right\}=\left\{\begin{array}{l}
0 \\
0
\end{array}\right\}
\end{aligned}
$$

$A 1$ and $A 2$ being nonzero, the determinant of the square matrix in this equation must be equal to zero as follows:

$$
\begin{aligned}
& \sinh ^{2} a H-\sin ^{2} a H-\cos ^{2} a H-2 \cosh a H \cos a H \\
& -\cosh ^{2} a H=0
\end{aligned}
$$

which leads to the reduced form equation of the frequencies vibration of the chimney

$$
\cos a H=-\left(\frac{1}{\cos a H}\right)
$$

The plot of functions $\cos \mathrm{aH}$ and $\frac{-1}{\cosh \mathrm{aH}}$ gives the values of aH corresponding to their crossing points for the root of Eq. (16) smaller than the third and give 1.875, 4.694 and 7.855 for $a H_{1}, a H_{2}$ and $a H_{3}$, respectively. For the roots higher than the third, an approximate value of $\mathrm{aH}$ is given by $\cos a H=0$, i.e.

$$
(a H)_{n} \cong \frac{\pi}{2}(2 n-1) \quad n=4,5,6 \ldots
$$

Introducing the value of aH into the expression of the a parameter, the corresponding circular frequencies can be obtained through the following relation

$$
\omega_{n}=(a H)_{n}^{2} \sqrt{\frac{E I}{\bar{m} H^{4}}}
$$

for which $\mathrm{E} I \mathrm{~m}$ and $H$ equal $2010^{9} \mathrm{~Pa}, 18.7 \mathrm{~m}^{4}, 11.3$ $10^{3} \mathrm{~kg} / \mathrm{m}$ and $65 \mathrm{~m}$, respectively.

This relation provides values of frequency resonance to 0.77 and $4.78 \mathrm{~Hz}$, corresponding to the fundamental $(n=1)$ and to the first higher resonance mode, respectively, close to the experimental values obtained by in-situ measurements of building vibration.

Then, the previously obtained conditions used to resolved Eq. (14) (i.e. $\mathrm{A} 3=-\mathrm{Al}$ and $\mathrm{A} 4=-\mathrm{A} 2$ ) and the expression of $\mathrm{A} 2$ in terms of $\mathrm{A} 1$ derived from Eq. (14) can be introduced to Eq. (11), and the mode-shape expression of Equation (11) takes now the form

$$
\begin{aligned}
\frac{\phi(x)}{A_{1}}= & \cos a H-\cosh a H-\frac{\cos a H+\cosh a H}{\sinh a H+\sinh a H} \\
& \times(\sin a H-\sinh a H)
\end{aligned}
$$

from which one obtains the corresponding modeshape functions substituting separately the frequencyequation roots for aH into this expression.

Once the frequencies and mode shapes are defined, the physically permissible displacement pattern can be made up by superposing appropriate modal amplitudes $Y n(t)$ of the vibration mode shapes for the structure, that comes down to the mode-superposition analysis expressed as

$$
v(x, t)=\sum_{i=1}^{\infty} \phi_{i}(x) Y_{i}(t)
$$

To evaluate the contribution of mode $\mathrm{n}$ in any arbitrary shape $v(x, t)$, this equation is multiplied by $\phi_{n}(x) m(x)$ on both sides and integrated, that gives results entirely equivalent to the discrete parameter expression (Clough and Penzien, 1993). The expression of the $\mathrm{Yn}(\mathrm{t})$ coordinates can be now expressed under matrix form and takes the form

$$
Y n(t)=\frac{\phi_{n}^{T} m v(t)}{\phi_{n}^{T} m \phi_{n}}
$$

By analogy with the undamped SDOF system (Eq. (2)), and considering a constant damping ratio $\xi=\xi_{n}$, the 
damped free-vibration response of the tower can be expressed in the form

$$
\begin{aligned}
& Y_{n}(t)\left[Y_{n}(0) \cos \omega_{\mathrm{Dn}} t+\frac{Y_{n}(0)+Y_{n}(0) \xi_{n} \omega_{n}}{\omega_{\mathrm{Dn}}} \sin \omega_{\mathrm{Dn}} t\right] \\
& \quad \times \exp \left(-\xi_{n} \omega_{n} t\right)
\end{aligned}
$$

where $\omega_{\operatorname{Dn}}=\omega_{\mathrm{n}} \sqrt{1-\xi_{\mathrm{n}}^{2}}$. Damping ratio has been evaluated using the randomdec method (Dunand et al., 2002) applied to the in-situ measurements of ambient vibrations at the top of the chimney. This method assumes the motion of the structures submitted to ambient noise is composed of its random response to the excitation and of its free-vibration response. By stacking ambient vibration time windows recorded at the building top, it is possible to build up the damped freevibration response of the structure from which it is easy to evaluate the damping factor by the so-called logarithmic decrement method (Clough and Penzien, 1993). In the case of the chimney, this method led to a value of $1.0 \%$. Initial conditions expressed in matrix form of the discrete parameter formulation are

$$
Y_{n}(0)=\frac{\phi_{n}^{T} m v(0)}{\phi_{n}^{T} m \phi_{n}} \quad \dot{Y}_{n}(0)=\frac{\phi_{n}^{T} m \dot{v}(0)}{\phi_{n}^{T} m \phi_{n}}
$$

This formulation supposes that the chimney is considered as a discrete-parameter system, the terms of the diagonal mass matrix $\mathbf{m}$ being equivalent then to the uniform mass per unit length, and the initial conditions vectors $\mathrm{v}(0)$ and $\dot{\mathrm{v}}(0)$ being applied to the gravity centre of each discrete mass. After generating the freevibration response for each mode $\mathrm{Y}_{\mathrm{n}}(\mathrm{t})$, the displacement of the tower in the geometric coordinates can be evaluated using Equation (20) which leads to

$$
\begin{aligned}
v(t) & =\phi_{1} Y_{1}(t)+\phi_{2} Y_{2}(t)+\ldots+\phi_{n} Y_{n}(t) \\
& =\Phi Y(t)
\end{aligned}
$$

The vector of elastic forces $f_{s}$ that resist the deformation of the structure are then given directly in matrix form by

$$
f_{S}(t)=m \Phi\left\{\omega_{n}^{2} Y_{n}(t)\right\}
$$

The base shear force $V_{0}(t)$ of the system is then given by the sum of all the discrete forces applied at the $N$ gravity center of the discrete mass, i.e.,

$$
V_{0}(t)=\sum_{i=1}^{N} f_{S i}(t)
$$

and the resultant overturning moment $M_{0}(t)$ at the base of the building is

$$
M_{0}(t)=\sum_{i=1}^{N} x_{i} f_{S i}(t)
$$

where $x_{i}$, is the height of the gravity center of discrete mass $i$ above the base.

The second step of our analysis amounts to considering that these base forces are seismic sources applied at the surface of the soil. The ground motion produced by the vibrating chimney is then computed using the wave number based Hisada's code (Hisada, 1994, 1995) that enables to consider sources and receivers at the same depth. The induced ground motion is computed at the outer array sites (Figure 2). Since we did not have any sensor on the structure during the array experiment to account for the actual structure excitation (internal excitation and/or wind forces characteristics), the tower is forced into free-vibration by an equivalent static force applied at the top of the structure, which induces a static displacement of unit amplitude $\mathrm{U}_{0 \mathrm{I}}$ at the top. The initial displacement along the discrete-mass system is given considering the initial deflected shape $\Psi(\mathrm{x})$ and the static displacement $U_{0 \mathrm{I}}$

\begin{tabular}{|c|c|c|c|c|c|c|}
\hline Profile & $\begin{array}{l}\text { Density } \\
\left(\mathrm{kg} / \mathrm{m}^{3}\right)\end{array}$ & $\begin{array}{l}\text { P-wave } \\
\text { velocity } \\
(\mathrm{m} / \mathrm{s})\end{array}$ & $\begin{array}{l}\text { S-wave } \\
\text { velocity } \\
(\mathrm{m} / \mathrm{s})\end{array}$ & $Q_{P}$ & $Q_{S}$ & $\begin{array}{l}\text { Thickness } \\
\text { (m) }\end{array}$ \\
\hline layer 1 & 1700 & 1850 & 700 & 100 & 50 & 700 \\
\hline layer 2 & 2500 & 5600 & 3200 & 200 & 100 & $\infty$ \\
\hline layer 1 & 1500 & 1500 & 300 & 40 & 20 & 15 \\
\hline layer 2 & 1700 & 1700 & 700 & 100 & 50 & 685 \\
\hline layer 3 & 2500 & 5600 & 3200 & 200 & 100 & $\infty$ \\
\hline
\end{tabular}

$$
v(x, 0)=\Psi(x) U(0)=\left(1-\cos \frac{\pi x_{i}}{2 H}\right) U_{0 \mathrm{I}}
$$

while the initial velocity vector $\dot{v}(x, 0)$ is null. The excitation is applied to the tower every $45^{\circ}$ in order to produce an isotropic nature of the input solicitation.

Table 2. Two geotechnical profiles in the Grenoble basin assumed in the outer array 


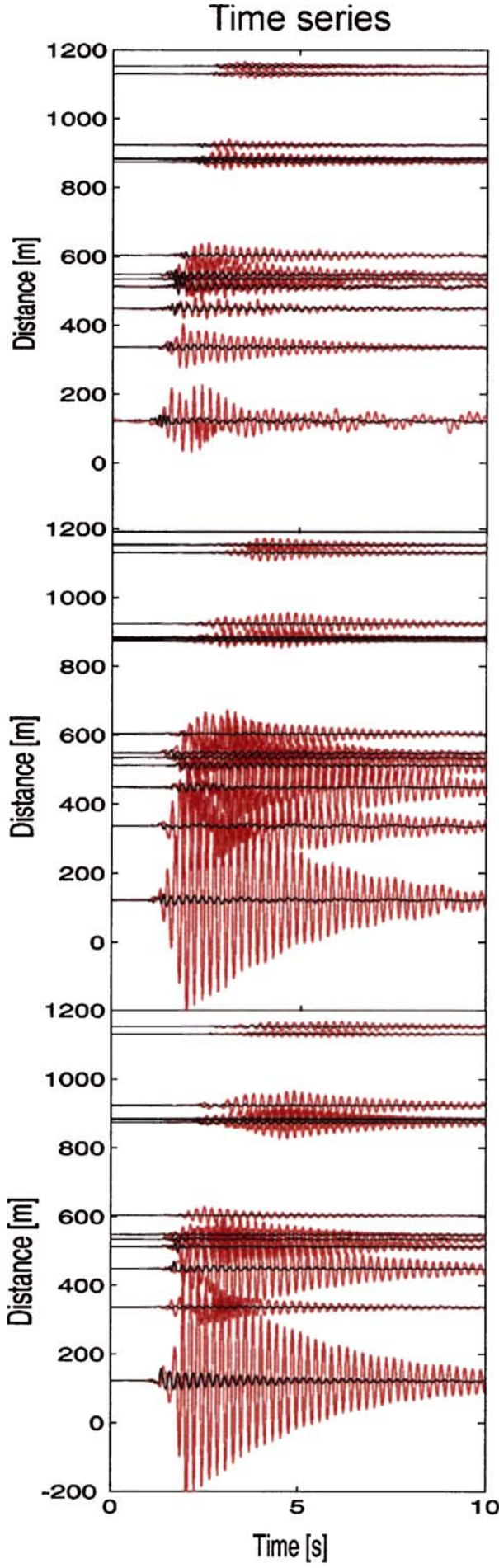

- Geotechnical profile A

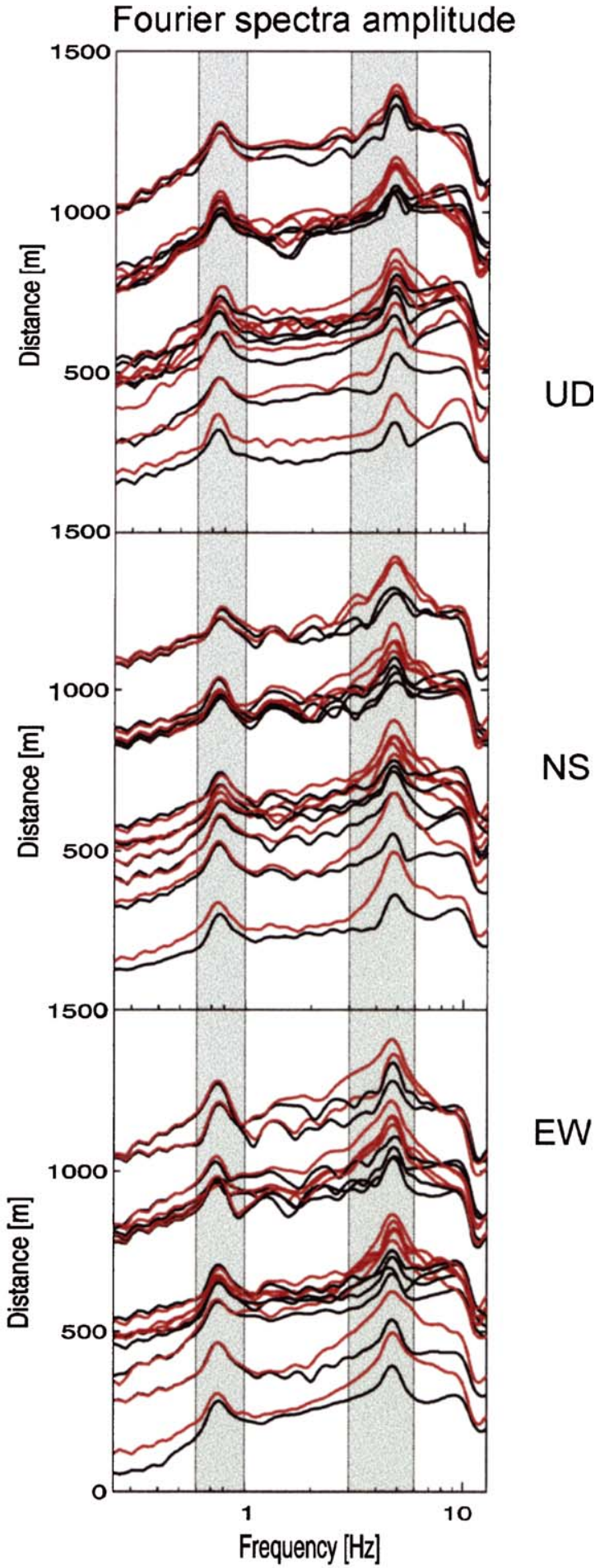

Geotechnical profile B

Figure 12. Simulated noise bursts: time series (left panel) and their corresponding Fourier spectra amplitude (right panel) as a function of the chimney-to-sensor distance using the A (black lines) and the B (red lines) geotechnical profiles (Table 2). The logarithmic value of the Fourier amplitude spectra is used here. The gray shaded area indicates the $0.7-1 \mathrm{~Hz}$ and the $3-6 \mathrm{~Hz}$ frequency band. 

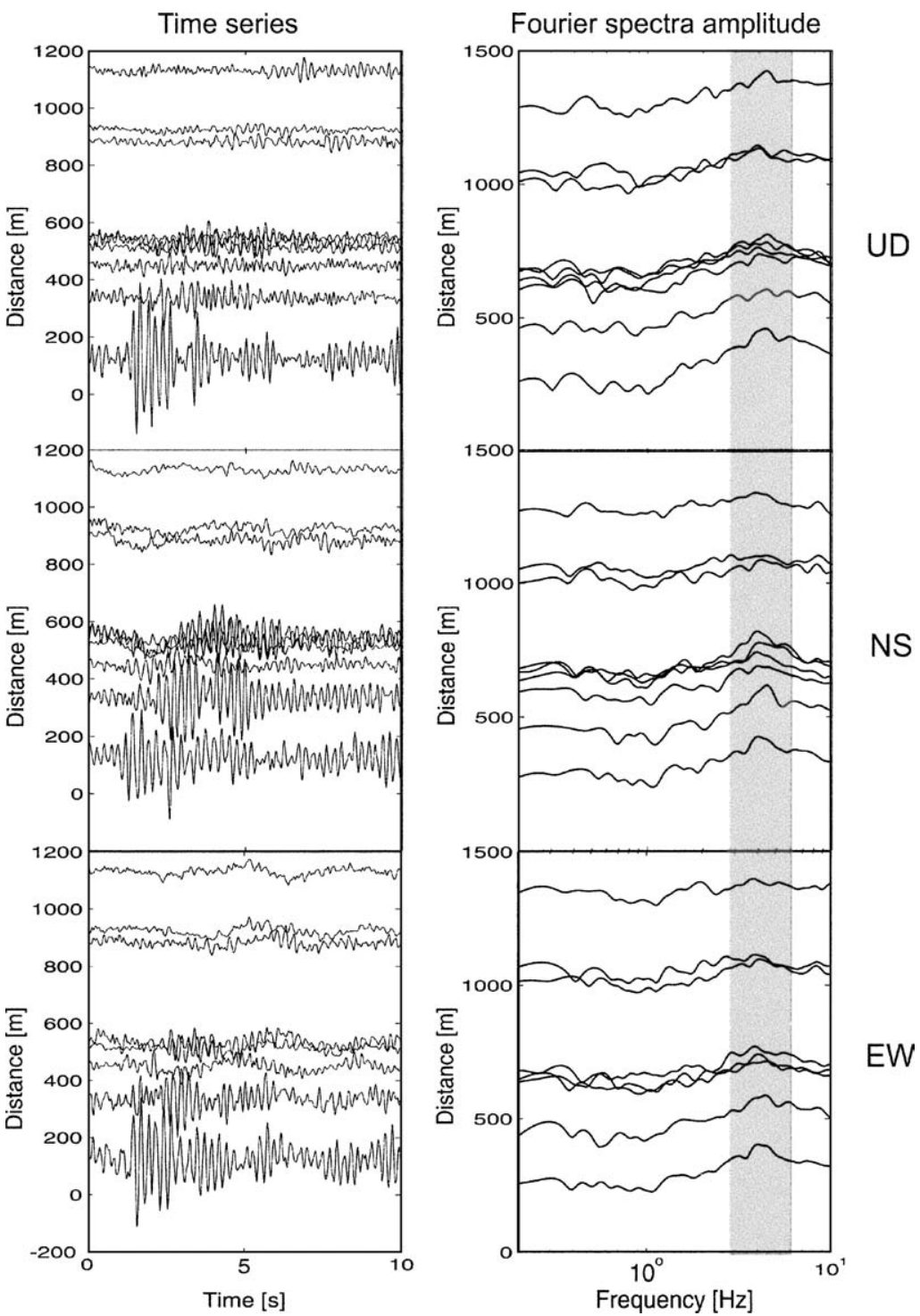

Figure 13. Time series (left panel) and their corresponding Fourier spectra amplitude (right panel) as a function of the chimney-to-sensor distance of the observed noise bursts previously presented in Figure 3b. The logarithmic value of the Fourier amplitude spectra is used here. Time series are band-pass filtered between 0.1 and $10 \mathrm{~Hz}$. The gray shaded area indicates the 3-6 Hz frequency band.

For the noise bursts simulation, two 1D soil profiles have been considered that includes or not a $15 \mathrm{~m}$ thickness topmost layer overlaying the deep sediment fill (Table II). As previously explained, the deposit thickness should vary from 15 to $30 \mathrm{~m}$ throughout the outer array. For the simulation, the thickness of the surficial layer was chosen such as to provide a resonance frequency of the soil $(5 \mathrm{~Hz})$ close to the first higher vibration mode of the modelled chimney $(4.78 \mathrm{~Hz})$.

As shown on computed time series and their corresponding Fourier spectra amplitude in Figure 12, vi- brations of the tower induce seismic waves propagating into the soil at the fundamental and the first higher harmonic vibration frequencies of the chimney. Nevertheless, even if both frequencies are observed up to the farthest station from the structure, the amplitude of the ground motion at $5 \mathrm{~Hz}$ is considerably higher in case of the soil profile that includes the thin topmost layer (profile $\mathrm{B}$ ). This is the result of the coincidence between the soil and the structure frequencies, which is the one of the most important factors controlling the induced motion at large distances (Guéguen et al., 2002). Figure 13 

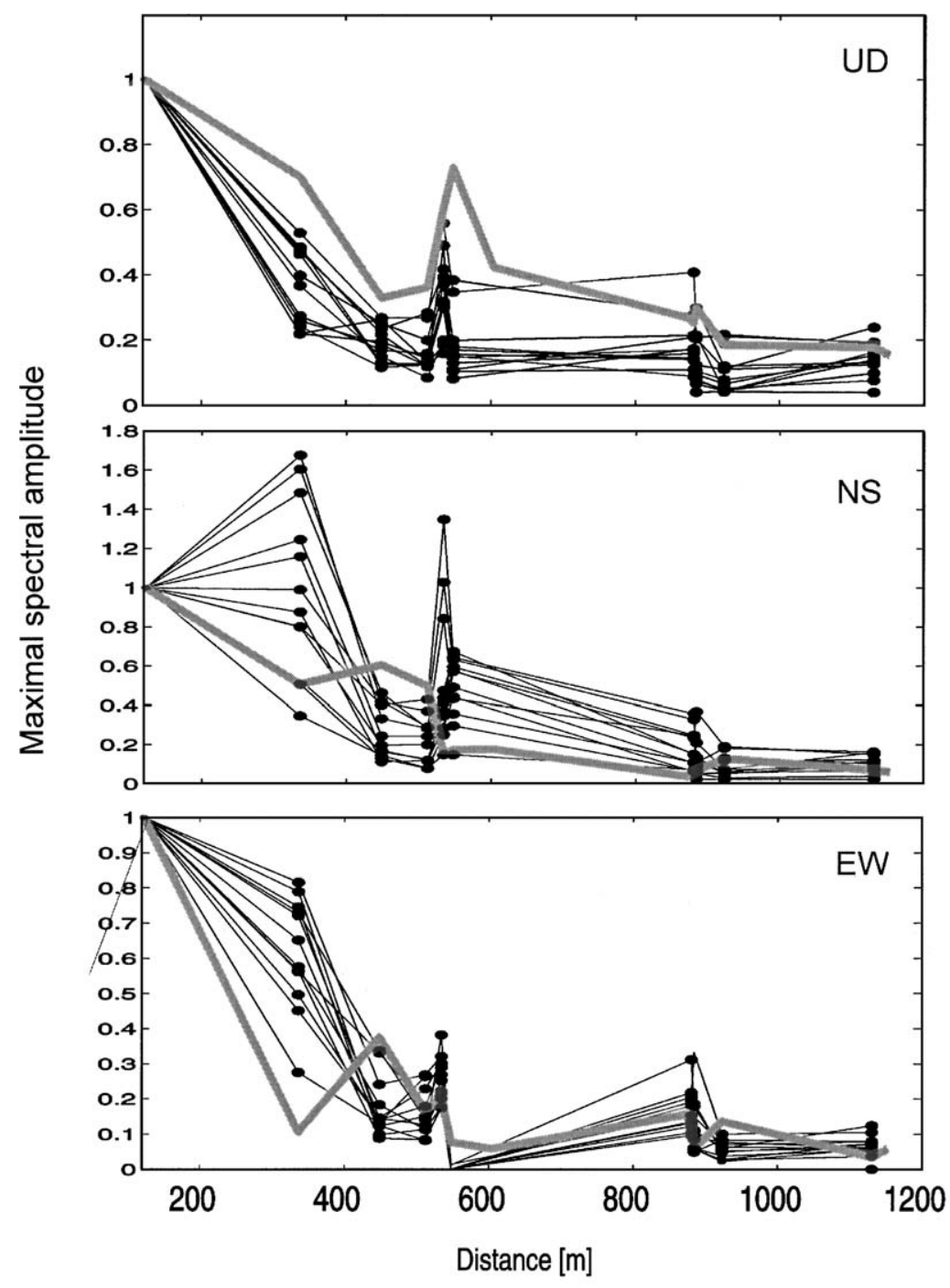

\section{Experimental data}

\section{Simulated data}

Figure 14. Maximal Spectral Amplitude (MSA) values of the simulated energy bursts using geotechnical profile B (thick line) and twelve observed bursts (thin lines and dots) recorded at the array sites as function of the chimney-to-arrray sites distance. The. MSA are normalized by the MSA at the ROBE station.

displays the time series and the corresponding Fourier spectra amplitudes of the burst presented in Figure $6 b$. No energy in the Fourier spectra amplitude is observed at $0.8 \mathrm{~Hz}$ even at the closest seismic sensors from the chimney. Such lack of energy at $0.8 \mathrm{~Hz}$ is also observed on the Fourier amplitude spectra of 12 bursts displayed in Figure 11. One can thus reasonably assume the need of the topmost thin layer to reproduce over very long distances the energetic noise bursts through trapping wave effects. Finally, the maximal spectral amplitude (MSA) decay from the ROBE station computed using the synthetic signals generated for the geotechnical profile B (Table 2) is compared with the MSA observed using the 12 bursts previously defined. For both synthetic and actual noise bursts, time window length is fixed to $10 \mathrm{~s}$ from the approximate bursts onset and time signals were bandpass-filtered between 3 and $6 \mathrm{~Hz}$. Because of the arbitrary amplitude of the external solicitation used in the simulation to force into vibration the tower (see before), MSA have been normalized by the value at the ROBE station. The MSA decaying shape is similar for both simulated and observed noise bursts and 
reproduces the 500 and $900 \mathrm{~m}$ singular distances that are related to the chimney-array sites geometry. Such consistencies between simulation and observation argue once more the anthropic origin of the observed noise bursts.

\section{Conclusions}

As already shown in Guéguen et al. (2002), the effect of the urban environment has to be accounted for in site effects estimation. The energy back-released into the soil through soil-structure interaction can indeed produce wave trains of significant amplitude over large distances, especially in case of coincidence between the structure and the soil resonance frequencies. Observational and numerical analysis of some energetic noise waveforms that appear within the $3-5 \mathrm{~Hz}$ frequency band in the Grenoble city have provided strong insights that the first higher mode of vibration of a chimney might be hold responsible of such energetic noise waveforms generation. The subsequent radiated waves should then propagate over large distances thanks to a trapping wave effects within a topmost sedimentary layer whose fundamental resonance frequency is close to the first higher resonance mode of the structure. Considering 1) that the resonance frequency of the topmost layer falls unfortunately into the frequency range of most of the buildings, and 2) that the noise bursts presented in this paper have been generated by a low excitation level, one may suspect stronger structure-soil interaction effects during moderate or strong seismic motion. This might thus significantly modify the urban free-field motion and should be taken into account in local seismic hazard assessment studies.

\section{Acknowledgements}

We are thankful to S. Bonnefoy-Claudet, J.-L. Chatelain and F. Dunand for their help in the field. We also thank A. Zerva for providing the original MUSIC code, and the two anonymous reviewers for their fruitful comments on the manuscript. Most of the computations were performed at the Service Commun de Calcul Intensif de 1'Observatoire de Grenoble (SCCI). This work was supported by the Pole Grenoblois des Risques Naturels, the "Programme National de Recherche sur la Prévision des Risques Naturels" of the Institut des Sciences de l'Univers du CNRS and by the ACI-CATNAT program of the Education French Ministry.

\section{References}

Auger, F. and Flandrin, P., 1995, Improving the readability of timefrequency and time-scale representations by reassignment methods, IEEE Trans. Signal Proc. 43(5), 1068-1089.

Bard, P.-Y., 1998, Microtremor measurement: A tool for site effect estimation? The effects of surface geology on seismic motion, In: Irikura, K., Kudo, K., Okada, H. and Sasatani, T. (eds.), Balkema, Rotterdam, pp. 1251-1279.

Bettig, B., Bard, P.-Y., Scherbaum, F., Riepl, J., Cotton, F., Cornou, C. and Hatzfeld, D., 2001, Analysis of dense array measurements using the modified spatial auto-correlation method (SPAC), Application to Grenoble area, Bull. Geof. Teor. Appl. 42, 3-4, 281304.

Chatelain, J.L., Guéguen, P., Guillier, B., Fréchet, J., Bondoux, F., Sarrault, J., Sulpice, P. and Neuville, J.M., 2000, CityShark: A user-friendly instrument dedicated to ambient noise (microtremor) recording for site and building response studies, Seism Res Lett. 71, 6, 698-703.

Clough, R.W. and Penzien, J., 1993, Dynamics of structures. 2nd ed, MacGraw-Hill, Inc Editor, 739 pp.

Cornou, C., 2002, Traitement d'antenne et imagerie sismique dans 1'agglomération grenobloise (alpes françaises): implications pour les effets de site, $\mathrm{PhD}$ Dissertation, Université Joseph Fourier, Grenoble, 260 pp (in French).

Cornou, C., Bard, P.-Y., and Dietrich, M., 2003a, Contribution of dense array analysis to the identification and quantification of basin-edge induced waves. Part I: Methodology, Bull. Seism. Soc. Am. 93(6) 2604-2623.

Cornou, C., Bard, P.-Y. and Dietrich, M., 2003a, Contribution of dense array analysis to the identification and quantification of basin-edge induced waves, Part II: Application to Grenoble basin (French Alps), Bull. Seism. Soc. Am. 93(6) 2624-2648.

Dunand F., Bard, P.Y., Chatelain, J.-L., Guéguen, P., Vassail, T. and Farsi, M.N., 2002, Damping and frequency from Randomdec method applied to in situ measurements of ambient vibrations. Evidence for effective soil structure interaction, Proceedings of the 12th European Conference on Earth Engineering, paper no. 869, London, UK.

Guéguen, P., Chatelain, J.-L., Guillier, B., Yepes, H. and Egred, J., 1998, Site effect and damage distribution in Pujili (Ecuador) after the 28 March 1996 earthquake, Soil. Dynamics Earthquake Eng. 17, 329-334.

Guéguen, P., Bard, P.-Y. and Oliveira, C.S., 2000a, Near to distant motions from an isolated RC-building model: experimental and numerical approaches, Bull. Seism. Soc. Am. 90(6) 14641479.

Guéguen, P., Chatelain, J.-L., Guillier, B. and Yepes, H., 2000b, An indication of the soil topmost layer response in Quito (Ecuador) using H/V spectral ratio, Soil. Dynamics Earthquake Eng. 19, 127-133.

Guéguen, P., Bard, P.-Y. and Chavez-Garcia, F.J., 2002, Site-City Interaction in Mexico City-Like environments: An Analytical Study, Bull. Seism. Soc. Am. 92(2) 794-811.

Hisada, Y., 1994, An efficient method for computing Green's functions for a layered half-space with sources and receivers at close depths (part I), Bull. Seism. Soc. Am. 84, 1456-1472.

Hisada, Y., 1995, An efficient method for computing Green's functions for a layered half-space with sources and receivers at close depths (part II), Bull. Seism. Soc. Am. 85, 1080-1093. 
Ivanovic, S.S., Trifunac, M.D. and Todorovska, M.I., 2000, Ambient vibration tests of structures: A review, Bull Indian Soc Earthquake Tech, Special issue on experimental methods.

Kanamori, H., Mori, J., Anderson, D.L. and Heaton, T.H., 1991, Seismic excitation by the space shuttle Columbia, Nature 349, 781-782.

Jennings, P.C., 1970, Distant motions from a building vibration test, Bull. Seism. Soc. Am. 60, 2037-2043.

Lebrun, B., 1997, Les effets de site: Etude expérimentale et simulation de trios configurations, PhD Dissertation, Université Joseph Fourier, Grenoble, 208 pp (in French).

Lebrun, B., Hatzfeld, D. and Bard, P.-Y., 2001, A site effect study in urban area: experimental results in Grenoble (France), Pageoph 158, 2543-2557.

Nakamura, Y., 1989, A method for dynamic characteristics estimation of subsurface using microtremor on the ground surface, $Q R$ of R.T.R. 30-1.
Nicoud, G., Royer, G., Corbin, J.-C., Lemeille, F. and Paillet, A., 2002, Glacial erosion and infilling of the Isère Valley during the recent Quaternary, Géologie de la France 4, 3949.

Pedersen, H.A., Mars, J. and Amblard, P.-O., 2002, Improving surface wave group velocity measurements by energy reassignment, Geophysics 68, 677-684.

Schmidt, R.O., 1981, A signal subspace approach to multiple emitter location and spectral estimation, Ph.D. Dissertation. 201 pp. Stanford University, Stanford, California.

Vallon, M., 1999, Estimation de I'épaisseur d'alluvions et sédiments quatemaires dans le région grenobloise par inversion des anomalies gravimétriques, IRSN/CNRS Internal Report, 34 pp (in French).

Wirgin, A. and Bard, P.-Y., 1996, Effects of buildings on the duration and amplitude of ground motion in Mexico city, Bull. Seism. Soc. Am. 86, 914-920. 